\title{
UTILIZAÇÃO DE HORTAS VERTICAIS COMO INSTRUMENTO DE EDUCAÇÃO AMBIENTAL NÃO FORMAL
}

\author{
Allan Guilherme Rodrigues de Souza ${ }^{1}$
}

Resumo: Este estudo resulta das ações do Projeto de Pesquisa Verticalizando, que consiste na utilização de hortas verticais para avaliar a Educação Ambiental em escolas do ensino fundamental. A partir dessa abordagem, o trabalho se dedica a verificar a eficiência do uso de hortas verticais como instrumento de Educação Ambiental não formal, de forma que a dinâmica utilizada nessa metodologia possa alavancar a consciência ambiental da sociedade, fazendo com que haja maior contato entre o homem e a natureza. Essa técnica é amplamente utilizada pelos projetos de Educação Ambiental, visto que é possível explorar diversos temas ambientais por ela. Nesse contexto 0 artigo evidenciará as vantagens da utilização deste instrumento e como o mesmo pode ser uma importante ferramenta de aprendizagem de Educação Ambiental não formal.

Palavras-chave: Hortas Verticais; Educação Ambiental; Educação Não Formal.

${ }^{1}$ Universidade Federal Rural do Rio de Janeiro. E-mail: agrs1996@gmail.com Revbea, São Paulo, V. 13, No 2: 388-395, 2018. 


\title{
Introdução
}

A questão ambiental é pauta de diversas discussões ao longo dos últimos anos, organizações governamentais e não governamentais buscam alternativas para obter soluções práticas para diminuir os impactos no meio ambiente, resultado das relações humanas com a natureza para obtenção de produtos.

\begin{abstract}
Essa visão utilitarista e inconsequente ameaça à extinção dos cursos da natureza não humana nas suas mais variadas formas de vida, assim como o fim da própria espécie humana diante da crescente deterioração da base material necessária ao desenvolvimento da sociedade, ou seja, o próprio meio ambiente. É dessas ameaças e das constatações dos diversos problemas ambientais que advém a atenção dada hoje à questão ambiental (SILVA, 2007, p.12)
\end{abstract}

O Brasil apresenta sérios problemas ambientais, que são sentidos pela população. Entretanto, a sociedade pouco participa das problemáticas ambientais. Segundo o ProNEA (2005): "A degradação dos solos, a poluição atmosférica e a contaminação de recursos hídricos são alguns dos efeitos nocivos observados. Os resíduos sólidos ainda são depositados em lixões, a céu aberto".

As estratégias de enfrentamento da problemática ambiental, para surtirem o efeito desejável na construção de sociedades sustentáveis, envolvem uma articulação coordenada entre todos os tipos de intervenção ambiental direta, incluindo neste contexto as ações em Educação Ambiental (ProNEA, 2005, pág. 17).

A implementação da Educação Ambiental deve ter como horizonte a formação de valores e ideais de relação com o meio ambiente. E para que se alcance um resultado satisfatório é importante à utilização de técnicas dinâmicas e do cenário ambiental de degradação que a população vivencia. Sendo nos ambientes mais deficientes de serviços públicos, espaço fundamental para que essa discussão deve seja mais aguçada, como expressa a ideia de Freire:

Por que não aproveitar a experiência que tem os alunos de viver em áreas da cidade descuidadas pelo poder público para discutir, por exemplo, a poluição dos riachos e dos córregos e os baixos níveis de bem-estar das populações, os lixões e os riscos que oferecem à saúde das gentes (FREIRE 1996 apud PERNAMBUCO; DA SILVA, 2009) 
Neste diapasão, a Educação Ambiental (EA) e suas diferentes abordagens, alcançam metodologias aplicadas no contexto de conscientizar a população dos problemas ambientais. Segundo Silva (2007) "a Educação Ambiental são as práticas educativas relacionadas à questão ambiental, e que se desenvolve na prática cotidiana dos que realizam o processo educativo".

No intuito de normatizar a ideia da Educação Ambiental, a lei no 9.795, de 27 de abril de 1999, dispõe nos artigos 1 e 2 a seguinte redação:

Art. 1ำ Entende-se por Educação Ambiental os processos por meio dos quais o indivíduo e a coletividade constroem valores sociais conhecimentos, habilidades, atitudes e competências voltadas para a conservação do meio ambiente, bem de uso comum do povo, essencial a sadia qualidade de vida e sua sustentabilidade.

Art. 2o A Educação Ambiental é um componente essencial e permanente da educação nacional, devendo estar presente, de forma articulada, em todos os níveis e modalidades do processo educativo em caráter formal e não formal (BRASIL, 1999, pág. 1).

A partir da Lei oㅜ 9.795/99 é possível observar duas abordagens para a Educação Ambiental, a formal e a não formal. A Educação Ambiental formal tem por pressuposto o planejamento e suas atividades dentro do currículo escolar, nos diferentes níveis de ensino. Nesse âmbito busca-se criar uma consciência ambiental no indivíduo, com o intuito de sensibiliza-lo, para que estabeleça com o meio ambiente uma relação harmônica (BRASIL, 1999). Não obstante, essa atuação geralmente é conservadora, ou seja, constitui-se em meio a uma prática pedagógica individualista, comportamentalista e consequentemente simplista por pensar que a soma das partes - indivíduos vão levar a transformação da sociedade (SILVA, 2007).

Gráfico 1: Evolução do número de escolas do ensino fundamental e de escolas que oferecem Educação Ambiental no Brasil entre os anos de 2001 - 2004. Fonte: Censo Escolar MEC/Inep.

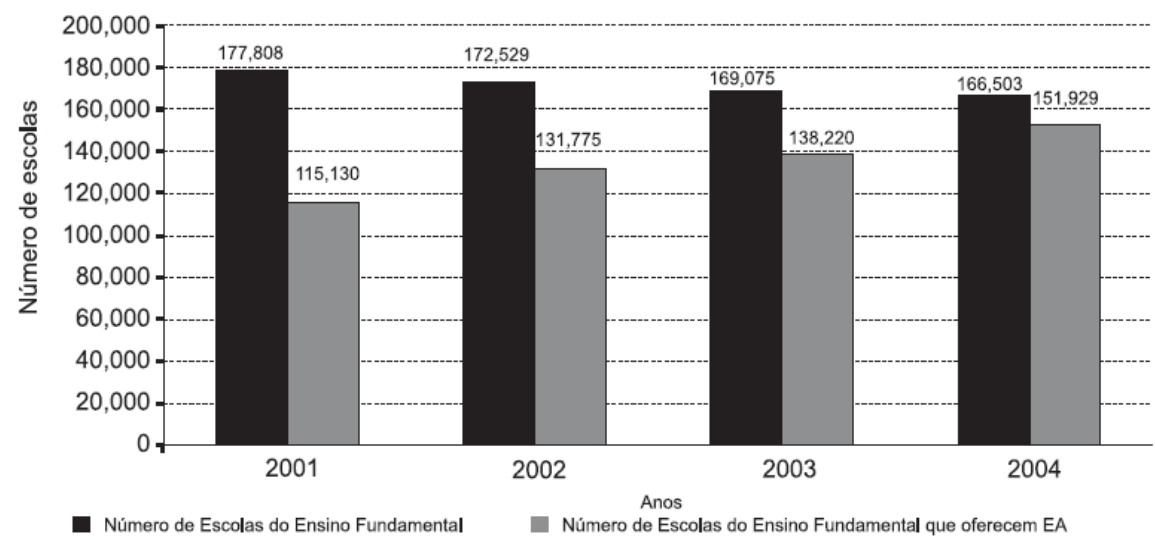

Revbea, São Paulo, V. 13, № 2: 388-395, 2018. 
Com base no Gráfico 1, vemos uma evolução no número de escolas ofertantes da Educação Ambiental no seu currículo, reverenciando a importância da legislação na consolidação da Educação Ambiental formal. Nesse contexto se faz necessário observar a eficácia da Educação Ambiental formal. $\mathrm{Na}$ atual conjuntura socioambiental brasileira, os frutos dessa abordagem da EA causam pouco impacto no modelo de sociedade a qual grande parte da população está inserida. É possível sentir essa problemática quando vivenciamos casos extremos de degradação ambiental, como, por exemplo: Desastre de Mariana/MG, crise da água no sudeste (2014-2015). E, a população permanece com a mesma consciência ambiental.

Dada essa realidade, a abordagem da Educação Ambiental não formal, se faz necessária, podendo surtir mais efeito, pela utilização de metodologias mais dinâmicas e pela participação de Organizações Não Governamentais, instituições de ensino superior, entre outras.

De acordo com o Artigo 13, da Lei no 9.795/99, que dispõe sobre a Política Nacional de Educação Ambiental (EA) "entendem-se por Educação Ambiental não formal as ações e práticas educativas voltadas a sensibilização da coletividade sobre as questões ambientais e a sua organização e participação na defesa da qualidade do meio ambiente."

O Brasil é um país possui alta demanda de consciência ambiental, visto isso, é necessária a utilização de técnicas dinâmicas que causem impacto em uma determinada população, nessa visão se insere as hortas verticais. Essa tecnologia funciona como um laboratório vivo, passível de diversas reflexões sobre os principais elementos naturais do planeta, abrangendo a teoria e prática de modo contextualizado, auxiliando no processo de aprendizado (MORGADO, 2006).

O Manual de hortas verticais (2012) revela a facilidade de se trabalhar com as hortas verticais em qualquer espaço físico, pois elas possuem estruturas leves, fáceis de serem construídas e possibilitam o plantio de ervas e hortaliças - conhecidas pela ampla maioria da sociedade -. Além da vantagem da mobilidade e uso de pouco espaço físico, podemos ressaltar o baixo custo da utilização de técnica.

Este trabalho tem por objetivo discutir a relevância da utilização de hortas verticais como ferramenta de Educação Ambiental não formal.

\section{Metodologia}

Para o desenvolvimento desse artigo, foram utilizados os estudos e experiências do Projeto de Pesquisa Verticalizando da Faculdade de Educação Tecnológica do Estado do Rio de Janeiro, campus Paracambi, realizado na Escola Municipal Luiz Cláudio Baranda, no município de Seropédica, com apoio da Secretária Municipal de Educação, Cultura e Esporte. O projeto utilizou o ciclo de pesquisa e ação de Lewin (1892-1947), no qual implementase uma ação e investiga-se o resultado dessa ação. A ação consistiu na 
criação de hortas verticais, para isso, foi empregado um método próprio de criação de hortas verticais (utilizando garrafas PET, solo, sementes e fitas) a fim de dinamizar o aprendizado de crianças e jovens dos ensinos fundamental e médio.

\section{Discussões}

A EA não formal ao longo dos últimos anos após a promulgação da Política Nacional de Educação Ambiental (1999) vem causando impactos positivos na sociedade, bem mais do que a EA formal. Essa relevância dar-seá pelos atores e técnicas utilizadas na concepção das atividades. Uma das metodologias mais utilizadas é o emprego de hortas verticais, para o auxilio no processo de aprendizagem, seja em ambiente formal ou não formal de ensino. Essa abordagem permite que avalie recursos naturais importantes, como: Solo, Água, Planta e Ar (SOUZA; JúNIOR; SANTOS, 2016). A Tabela 1, reflete a avaliação realizada pelo Projeto de Pesquisa Verticalizando, utilizando as hortas verticais, estabelecendo índices de avaliação, para verificar o conhecimento dos avaliados sobre os recursos naturais do planeta.

Tabela 1: Avaliação da percepção ambiental dos alunos do $4^{\circ}-5^{\circ}$ ano da EMLCB.

Fonte: Souza et al. (2015).

Avaliação da Percepcção Ambiental

\begin{tabular}{|c|c|c|c|}
\hline \multirow{2}{*}{ Fatores de Avaliação } & \multicolumn{3}{|c|}{ Indices de Avaliação } \\
\hline & Pouco & Médio & Alto \\
\hline Conhecimento da relação solo-planta-água-atmosfera & $\mathrm{x}$ & \multirow{7}{*}{$\mathrm{x}$} & \multirow{7}{*}{$\mathrm{x}$} \\
\hline Conhecimento da importância da água no planeta & $\mathrm{x}$ & & \\
\hline Conhecimento da importância das plantas & & & \\
\hline Conhecimento da importância do solo & $\mathrm{x}$ & & \\
\hline Conhecimento da interação solo-planta & $x$ & & \\
\hline Participação nas atividades do projeto & & & \\
\hline Interação com as práticas sustentáveis & & & \\
\hline
\end{tabular}

Nesse contexto a utilização de hortas verticais instrumentaliza ações de Educação Ambiental não formal, permitindo ao público alvo a interação direta com o meio ambiente, e o questionamento das relações naturais entre os recursos ambientais, potencializando a capacidade de aprendizado e conscientizando sobre a importância da preservação do ambiente.

O ativismo das ONG's, Projetos de pesquisa e Projetos de extensão, em prol da Educação Ambiental não formal em espaços formais de ensino, configura uma alternativa para a construção de uma consciência ambiental. 
" Históricamente, tem havido um ganho de qualidade na Educação Ambiental (EA) brasileira, no que se reflete no nível de organização da mesma dentro do país. Esse ganho é percebido na trajetória da EA no Brasil, que evolui de um contexto inicial de realização de ações pontuais espacial e temporalmente, para o estabelecimento de parcerias não formais (redes) e organização de projetos e programas de EA" ( ANDRADE, et al. 2014, p.824).

Complementando a linha de pensamento, a tabela 2 explicita a interação da comunidade com atividades de Educação Ambiental não formal, no ambiente escolar.

\begin{tabular}{|c|c|c|c|c|}
\hline $\begin{array}{l}\text { Brasil, Grandes Regióes e } \\
\text { Unidades da Fedraçăo }\end{array}$ & $\begin{array}{l}\text { Número de } \\
\text { Escolas que } \\
\text { oferecem EA }\end{array}$ & $\begin{array}{c}\text { Comunidade } \\
\text { colaborando na } \\
\text { manutençao de } \\
\text { hortas, pomares, } \\
\text { Jardins }\end{array}$ & $\begin{array}{l}\text { Comunidade } \\
\text { participando em } \\
\text { mutiråo de } \\
\text { limpeza da } \\
\text { escola }\end{array}$ & $\begin{array}{l}\text { Comunidade } \\
\text { participando em } \\
\text { mutirão para } \\
\text { manuttenção da } \\
\text { estrutura fisica da } \\
\text { escolla }\end{array}$ \\
\hline Brasil & 151929 & 8,80 & 17,92 & 10.46 \\
\hline Norte & 20887 & 6.27 & 38,90 & 18,76 \\
\hline Acre & 1308 & 6.12 & 14,53 & 12,31 \\
\hline Amazonas & 4163 & 10,26 & 49,96 & 22,89 \\
\hline Amapá & 656 & 10,06 & 39,79 & 22,41 \\
\hline Pará & 10684 & 2,85 & 36,95 & 16,64 \\
\hline Rondõnia & 1676 & 10,44 & 57,82 & 30,67 \\
\hline Roraima & 559 & 12,34 & 42,75 & 30,77 \\
\hline Tocantins & 1841 & 10,16 & 23,74 & 10,48 \\
\hline Nordeste & 69248 & 3,93 & 10,56 & 4,74 \\
\hline Alagoas & 3103 & 2,13 & 5,06 & 2,22 \\
\hline Bahia & 19372 & 4,48 & 11,32 & 4,81 \\
\hline Ceará & 10014 & 7,40 & 18,22 & 9,42 \\
\hline Maranhăo & 9556 & 3,03 & 13,54 & 5,21 \\
\hline Paralba & 6071 & 83,09 & 5,63 & 1,94 \\
\hline Pernambuco & 9440 & 1,84 & 8,41 & 4,33 \\
\hline Piaui & 6368 & 3,91 & 3,47 & 1,10 \\
\hline Rio Grande do Norte & 3219 & 1,84 & 8,64 & 3,54 \\
\hline Sergipe & 2105 & 4,47 & 9,83 & 6,18 \\
\hline Centro-Oeste & 7778 & 14,28 & 21,45 & 11,69 \\
\hline Distrito Federal & 748 & 16,04 & 14,84 & 12,97 \\
\hline Goiás & 3729 & 16,76 & 22,45 & 9,48 \\
\hline Mato Grosso do Sul & 1037 & 8,00 & 10,13 & 7,62 \\
\hline Mato Grosso & 2264 & 12,50 & 27,16 & 16,17 \\
\hline Sudeste & 36094 & 11,60 & 14,37 & 11,36 \\
\hline Espirito Santo & 3093 & 7,34 & 21,40 & 17,23 \\
\hline Minas Gerais & 12794 & 12,61 & 9,62 & 9,03 \\
\hline Rio de Janeiro & 7214 & 8,91 & 8,91 & 7,64 \\
\hline Säo Pado & 12992 & 13,11 & 20,41 & 14,33 \\
\hline Sul & 17922 & 22,56 & 27,53 & 20,54 \\
\hline Paraná & 6002 & 14,98 & 15,83 & 11,61 \\
\hline Rio Grande do Sul & 7859 & 27,19 & 36,16 & 26,57 \\
\hline Santa Catarina & 4061 & 24,82 & 28,12 & 22,09 \\
\hline
\end{tabular}

Tabela 2: Inserção das escolas em atividades comunitárias - Brasil, Grandes Regiões e nas Unidades da Federação - 2004. Fonte: Censo Escolar, MEC/Inep.

Essas atividades não formais de ensino possibilitam uma interação entre as comunidades interna e externa, no âmbito escolar, de forma a pensar o ambiente por outra concepção. E, a prática da Educação Ambiental entre essas comunidades utilizando as hortas verticais, configura-se um importante instrumento de aprendizagem. Neste diapasão Natércia (2007) reflete que, a possibilidade de proporcionar as crianças contato direto com a natureza a partir do plantio, manuseio e observação de plantas, provoca comportamentos 
positivos desde a infância até a idade adulta em relação à preservação ambiental. A Figura 1 evidencia esse contato direto com a natureza através das hortas verticais.

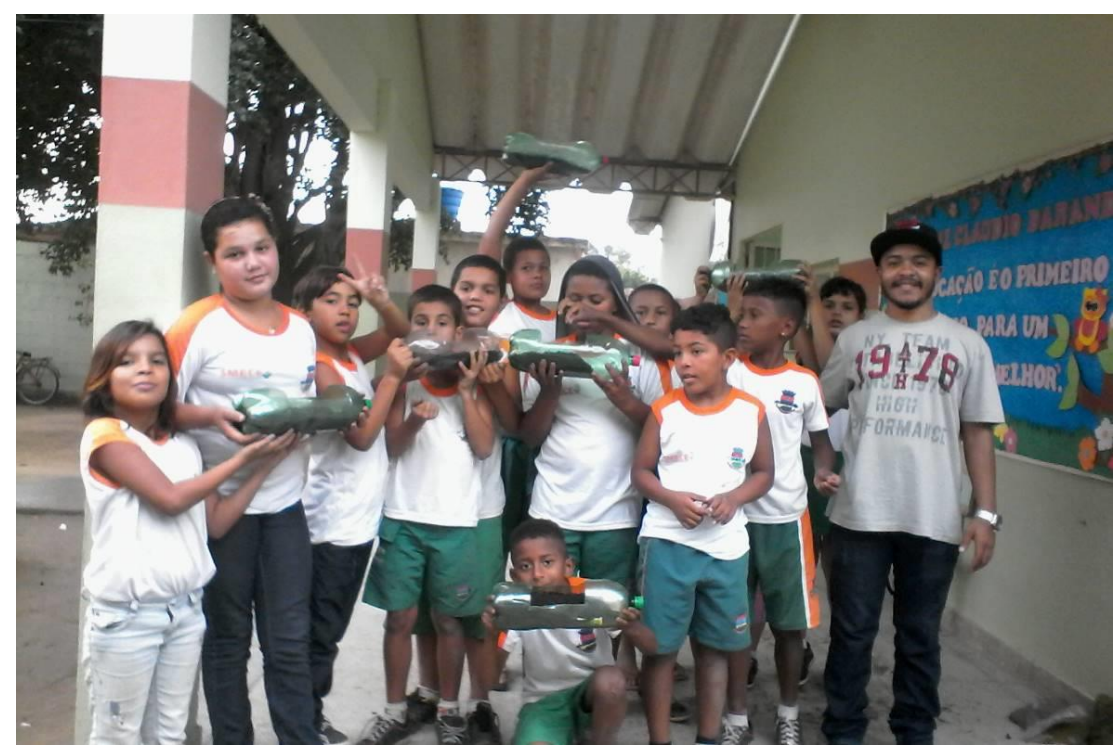

Figura 1: Plantio de hortaliças em garrafas pet. Fonte: Dados dos autores.

\section{Conclusão}

Portanto, com base nos dados apresentados, é possível observar que a problemática brasileira, no que tange a Educação Ambiental, é a efetiva aplicação de métodos interativos, que propiciem uma real interação ambiental com a população. A utilização de hortas verticais na Educação Ambiental não formal vem como alternativa eficiente e eficaz, sendo fundamental sua ampliação a partir dos primeiros níveis de ensino, para que haja uma real formação de uma consciência ambiental na sociedade.

Com as hortas verticais, é possível ter uma visão interdisciplinar e integrada do meio ambiente. Com isso os benefícios alcançados com esse instrumento de Educação Ambiental não formal vão desde a produção de alimentos a assuntos de economia doméstica, agregando na concepção de uma nova relação entre homem e natureza.

Desta forma, é essencial a manutenção e o incentivo aos projetos que trabalhem com hortas verticais na Educação Ambiental não formal, visto que, são expressivos os impactos positivos desta ação para a sociedade. Tendo como pressuposto a geração de uma sociedade mais consciente e um ambiente mais harmônico. 


\section{Referências}

ANDRADE, D. F. Implementação da Educação Ambiental em escolas: uma reflexão. Revista Eletrônica do Mestrado em Educação Ambiental, Fundação Universidade Federal do Rio Grande. v. 4.out/nov/dez 2000.

ANDRADE, D.F; LUCA, A. Q; CASTELLANO, M; RISSATO, C. G; SORRENTINO, M. Da pedagogia à politica e da politica à pedagogia: uma abordagem sobre a construção de politicas públicas em Educação Ambiental no Brasil. Ciênc. Educ., Bauru, v. 20,n. 4, p. 817-832, 2014.

Brasil. Lei no 9.975/99 - Lei da Educação Ambiental. Disponível em: $<$ http://www.mma.gov.br/port/conama/legiabre.cfm?codlegi=321>. Acesso em $15 / 10 / 2016$, as $17 \mathrm{~h} 00 \mathrm{~min}$.

BRASIL. Programa nacional de Educação Ambiental - ProNEA / Ministério do Meio Ambiente, Diretoria de Educação Ambiental; Ministério da Educação. Coordenação Geral de Educação Ambiental - 3 . ed - Brasília : Ministério do Meio Ambiente, 2005.

Manual de Hortas Verticais, IDDS - 2012. Disponível em: $<$ http://www.usp.br/agen/wp-content/uploads/IDDS manual-de-hortasverticais julho-2012.pdf>. Acesso em: 17 out. 2016, as 22h00min.

MORGADO, F.S. A horta escolar na Educação Ambiental e alimentar: experiência do Projeto Horta Viva nas escolas municipais de Florianópolis. Universidade Federal de Santa Catarina. Centro de Ciências Agrárias. Curso de Agronomia. 2006.

NATÉRCIA, F. Infância próxima à natureza estimula preocupação ambiental na vida adulta. Ciência e Cultura, São Paulo, v. 59, n. 1, p. 22, 2007.

RAMOS, D.J; SENA, C.C.R.G; GOMES JUNIOR, E.C. Educando com a horta vertical: uma experiência teórico-prática com o solo. XX Congresso Latino Americano y XVI Congresso Peruano de la Ciencia Del Suelo. Cusco-Peru. 2014.

SILVA, V. A relação entre Educação Ambiental formal e não formal: Um estudo de caso do parque natural municipal da Taquara e as escolas do entorno. Monografia. Universidade do Estado do Rio de Janeiro - Faculdade de Educação da Baixada Fluminense - 2007

SOUZA, A.G.R; JÚNIOR, S.R.F; SANTOS, L.S. Avaliação da Educação Ambiental no ensino fundamental no município de Seropédica/RJ. Anais do V Simpósio de Gestão Ambiental e Biodiversidade, ITR/UFRRJ. Três Rios, 2016.

VEIGA, A; AMORIM, E; BLANCO, M. Um Retrato da Presença da Educação Ambiental no Ensino Fundamental Brasileiro: o percurso de um processo acelerado de expansão. Instituto Nacional de Estudos e Pesquisas Educacionais Anísio Teixeira, Brasília, 2005. 